\title{
LAS FUERZAS ARMADAS EN EL NUEVO CICLO DE LA VIDA POLÍTICA ESPAÑOLA (*)
}

\author{
Jesús Ignacio Martínez Paricio* \\ José Ramón Díaz Castro**
}

El Tribunal Militar que juzgó en Consejo de Guerra a los implicados en el golpe de Estado del 23 de Febrero de 1981 dictó sentencia en la primavera de $1982^{1}$. Se cumplió así uno de los objetivos del programa de gobierno de Leopoldo Calvo Sotelo, gobierno de centro derecha, Unión de Centro Democrático (UCD). Una vez conocida la sentencia el gobierno la recurrió ante el Tribunal Supremo ${ }^{2}$. El motivo nada tenía que ver con discrepancias respecto del procedimiento judicial o porque se pretendiera aumentar las condenas a los implicados. La razón se explica en términos históricos y de alta política. Se quiso demostrar que en el proceso de consolidación de la democracia en España la última palabra la dictaba el poder civil. El gobierno demostró un notable coraje político ${ }^{3}$. Se puso fin a la peculiar y desigual relación de las fuerzas armadas en la vida política española. En la historia contemporánea el poder militar, a pesar de sus carencias y limitaciones de todo tipo, siempre mostró su fortaleza frente al poder civil. Con el recurso ante el Tribunal Supremo terminaba lo que se puede denominar síndrome Balmes $^{4}$. Se resume con las propias palabras del ensayista: "No creemos que el poder civil sea flaco porque el militar sea fuerte; sino que, por el contrario, el poder militar es fuerte porque el civil es flaco... La fuerza del poder civil será la ruina del poder militar, que dejará de ser poder y pasará a ser una clase más del Estado" (Balmes, 1950. pp. 569-575).

* Profesor Titular de Sociología de la Universidad Complutense de Madrid. Miembro de la Asociación Castellano-Manchega de Sociología.

** Profesor de Sociología de la Universidad Rey Juan Carlos. Miembro de la Asociación Castellano - Manchega de Sociología. 
El del 23 de febrero fue el último golpe de Estado. Hubo otros intentos sin la contundencia de éste. El juicio fue utilizado por acusados, abogados defensores y simpatizantes como altavoz para seguir denunciando el modelo de sociedad democrática que se estaba consolidando. En los alegatos que se pronunciaron en las sesiones del juicio a favor de los golpistas y en un documento anónimo que circuló en esas fechas, redactado por un grupo de militares y civiles y dirigido al Rey en su condición de Jefe de las Fuerzas Armadas, tuvo lugar el último pronunciamiento militar en España.

Sin entrar en la valoración del proceso judicial la sentencia del juicio tuvo un claro sentido pedagógico que no ha sido destacado (Paricio, 1990 y 1991) La Constitución de 1978 sitúa a las Fuerzas Armadas en su Título Preliminar. De esta manera se reconoce la trascendencia de su papel en la defensa del modelo de sociedad avanzada que se describe en su Preámbulo. Los militares golpistas utilizaron este argumento en su defensa. Justificaron la acción en razón del estado de necesidad al que se había llegado por el desorden político vivido en los meses previos al golpe. Actuaron para salvar España, según sus declaraciones. Más allá de la demostración de los hechos juzgados la sentencia destacó que la defensa del orden constitucional recae en el comportamiento democrático de todos los españoles, junto con partidos políticos, sindicatos y organizaciones empresariales. Solo en situaciones extremas, reguladas por la propia Constitución, la defensa del orden constitucional debe ser competencia de las fuerzas armadas. Se argumentó en la sentencia que las fuerzas armadas están en el Estado, pero no son el Estado. Las fuerzas armadas tienen y administran la fuerza del Estado, pero no son depositarios del poder del Estado, el poder reside en la soberanía popular. La integración de las fuerzas armadas en el sistema político reclamaba la estabilidad del modelo pluralista, requisito propio de la normalidad de la vida política, al tiempo que la descentralización del Estado no debería poner en peligro la unidad nacional ${ }^{5}$. El apoliticismo de los militares se valoró en la sentencia como utopía inadmisible pues el militar es un ciudadano más. No se aceptaba que el militar pudiera participar en la política de los partidos ya que llevaría a la división de la institución militar. El sentido pedagógico de la sentencia sirvió para recomponer el sistema de valores de la organización militar.

El golpe de Estado también se debe entender como confrontación de dos conceptos del papel que corresponde a las fuerzas armadas en la sociedad. La sentencia puso en su lugar los pares conflictivos que se habían enfrentado. Se destacó la importancia de la disciplina como principio básico de la organización militar que debe estar por encima del honor militar. En el ejercicio de la profesión el militar debe prestar obediencia nada más que a sus jefes orgánicos. El compañerismo se consideró valor fundamental para el buen ejercicio de la profesión sin olvidar que debe estar apoyado en el principio de la lealtad al superior. A partir de estos principios se asegura el buen funcionamiento de la organización militar, considerando negativo la actuación en términos corporativos. La opinión propia debe ser estimulada 
por los superiores pues de esta manera se gana la confianza de los subordinados y se asegura la eficacia de la organización. Una vez manifestada la opinión particular el criterio propio debe quedar a un lado cuando se exige el cumplimiento de la doctrina oficial. Del pasado se dijo que debería ser asumido de manera que se proyectara de forma positiva sobre el presente y, de manera especial, sobre el futuro de las fuerzas armadas. La historia en ningún caso podía hipotecar el futuro de las fuerzas armadas. Los militares no podían romper con su tradición pero tampoco podían mitificar el pasado. Los símbolos y conceptos claves en la organización y cultura militar tenían que fortalecer la integración de las fuerzas armadas en la nueva sociedad que se abría paso. Las fuerzas armadas no podían seguir apropiándose del sentimiento patriótico, con sentido patrimonial y en beneficio propio, desvirtuándolo así de su verdadero sentido pues debe ser compartido por el resto de los ciudadanos.

En las horas de incertidumbre que siguieron al asalto del Congreso de los Diputados quedó resuelto el problema militar en España. Problema planteado en los términos políticos que se venían arrastrando desde mediados del siglo XIX. La solución se alcanzó de acuerdo con la propuesta de los españoles de la conciliación (García Escudero, 1987) Años antes Dionisio Ridruejo, uno de los españoles que pretendieron alcanzar ese objetivo con mayor vehemencia, lo describió de la manera que se indica. "El problema militar no puede ser ni podrá reducirse en España a disciplinarlo y reducirlo, sino mucho antes, habrá que implicarlo con la creación del Estado y la organización de unas fuerzas que no puedan ser sustituidas por él y que ganen al fondo inerte del país. Sólo entonces será posible que el Ejército español sea un instrumento sumiso y adaptado fielmente a su misión... Venció el Ejército (en la Guerra Civil) y ahora ya no se trata de medir el límite de su tolerancia sino de implicar su responsabilidad en la tarea de dar una salida a la situación creada por su iniciativa" (Ridruejo, 1964, pp.143-150)

En la tarde y noche del 23 de febrero de 1981 unos militares invadieron el Congreso y otros comenzaron movimientos de insubordinación para apoyarles. Otros militares mantuvieron un cauteloso silencio para tomar postura y actuar en función del resultado. La indagación policial y judicial no actuó frente a este tercer grupo del que poco se sabe y menos su número ${ }^{6}$. Frente a estas posturas la mayoría de los militares se mantuvieron en su sitio. Dejaron a un lado su estado de ánimo y la valoración personal de la situación política del momento, así como su identificación con algunos de los militares golpistas. Si las fuerzas armadas lo hubieran querido el golpe habría triunfado. Se demostró una vez más la importancia de contar con las personas adecuadas, profesionales, en los lugares y momentos oportunos. Funcionó la confianza en el mando y las fuerzas armadas se colocaron donde correspondía, en el lado de la defensa del orden constitucional. Quedó garantizado el proceso que terminó por consolidar el modelo de sociedad avanzada que deseaba la mayor parte de la población española. Uno de los errores fundamentales de los 
golpistas fue creer que la mayoría de la población estaba en contra del sistema democrático. Interpretaron de manera errónea las protestas de los ciudadanos contra el gobierno. Entendieron las críticas a los políticos como desprecio del sistema y las instituciones democráticas. Los datos de la opinión pública demostraban que la crítica lo era nada más que a la falta de eficacia de las personas. No entendieron que la denuncia pública era compatible con el deseo de mantener y consolidar la democracia parlamentaria. El golpe de Estado contó con el apoyo liviano de algún periódico poco influyente. Apenas se realizó manifestación alguna de apoyo a los militares golpistas por parte de personalidades relevantes y líderes de opinión. No hubo apoyo al golpe ${ }^{7}$. Eran pocos los querían la involución. Contra la voluntad mayoritaria poco podían hacer los tanques que salieron a la calle. En esas condiciones el triunfo del golpe habría exigido un extraordinario ejercicio de violencia que nadie quería, ni siquiera los más comprometidos. En la memoria colectiva permanecía el drama en el que terminó la guerra de ideas que se había desarrollado en la España de los años treinta (Castillejo, 1976) Las encuestas demostraban la necesidad del cambio civilizado. Nada más. Se deseaba un cambio pacífico y ordenado de acuerdo con las reglas de la democracia parlamentaria. En la encuesta cualitativa que se realizó a los altos mandos militares, entre 1973 y 1980, se reconoció que después de Franco España sería otra cosa. Algunos no les gustaba lo que imaginaban por venir, pero lo aceptaban. No discutían el qué de España, les preocupaba el cómo se iba a llegar a la nueva situación política. No se quería repetir los errores y el drama que habían vivido como jóvenes oficiales durante la guerra civil y el aislamiento posterior ${ }^{8}$.

Los meses que transcurrieron entre el intento del golpe de Estado y el juicio militar se produjo el cambio de tendencia en el ciclo antiguo de las fuerzas armadas españolas. En esos meses las fuerzas armadas adquirieron una nueva legitimidad otorgada en este caso por la opinión pública. Hasta ese momento las fuerzas armadas aparecían como grupo político de máxima influencia. Eran consideras como el poder fáctico del sistema político español. Se temía y se desconfiaba de las fuerzas armadas, y se desconocía casi todo de lo que pasaba en ellas. La situación era más grave cuando estas actitudes estaban presentes entre políticos e intelectuales ${ }^{9}$. En la opinión pública, a partir del día 24 de febrero, fue desapareciendo lentamente los recelos ante las fuerzas armadas y los militares ${ }^{10}$. Las fuerzas armadas comenzaron a verse como una organización más del Estado. Lo militar se empezó a valorar en términos de eficacia profesional ${ }^{11}$. Solucionado el problema militar, institucional y de carácter político, de legitimación, se consideró que había llegado el momento de las reformas en la organización militar con el fin de garantizar su eficacia profesional. Los gobiernos de centro habían sentado las bases. Se había creado el Ministerio de Defensa y se redactaron planes y proyectos para iniciar la modernización de las fuerzas armadas. En 1978, antes de la promulgación del texto constitucional, se aprobaron las Reales Ordenanzas para las Fuerzas Armadas como código de conducta de los militares en la nueva realidad política. En sentido estricto es un 
texto pre-constitucional que por esta razón plantea problemas fundamentales en algunas cuestiones del oficio militar (Paricio, 2001) Es un texto donde varios de sus artículos quedaron desfasados al poco tiempo de su aprobación. En su redacción no se podía imaginar que al poco tiempo iba a desaparecer el servicio militar obligatorio, que la mujer se incorporaría a la vida militar, o que las fuerzas armadas españolas actuarían cada vez más en misiones fuera del territorio nacional.

El gobierno del Partido Socialista (PSOE) inició las reformas con las que proponía alcanzar la mayor eficacia de las fuerzas armadas. Buscó la despolitización definitiva de las fuerzas armadas a través de la profesionalización. Como se reconoció más tarde las reformas se plantearon bajo el mantenimiento de estereotipos y tomando como referencia para el cambio a ejércitos europeos bien distintos al español. Proceso tan complejo se realizó en un ambiente de educada desconfianza ante los militares y mostrando un incómodo interés por las cuestiones de la seguridad y la defensa con las que necesariamente tenían que pechar ${ }^{12}$. Ante la contundencia de las sanciones los militares dejaron de manifestar sus opiniones y críticas en la prensa. Se convirtieron en los grandes mudos incluso en las cuestiones profesionales que les afectaban. En la organización militar se levantó un sonoro silencio hacia el exterior. Fue la manera torcida de entender la profesionalización militar. No todos salieron perdiendo, pero tampoco ganaron todos. Uno de los problemas más difíciles a los que tuvo que hacer frente el gobierno socialista fue celebrar el referéndum sobre la permanencia de España en la OTAN, y ganarlo. El PSOE, en su época de oposición, había centrado la campaña electoral en la promesa de paralizar el proceso de integración de España en la OTAN. Una vez asumida la responsabilidad de gobierno comprobó que los argumentos de la razón de Estado tenía que ponerlos por encima de los intereses del partido en la oposición ${ }^{13}$. En los primeros años de gobierno socialista las relaciones internacionales se plantearon en términos de ambigüedad calculada ${ }^{14}$. El pragmatismo modernizador que exigía la apertura de España al exterior convivía, en el PSOE y en el gobierno, con un confuso progresismo de izquierdas. Como resultado lógico de tan ilógica situación se produjo no pocas incomprensiones y sobresaltos dentro del país y con los socios comunitarios. Al final se tuvo que aceptar, algunos muy a su pesar, que compartir el destino político y económico europeo exigía asumir los costes y las cargas de la seguridad y la defensa europea. Se hizo poco para explicar de manera razonada el cambio de opinión.

Aplicar el plan de reformas previsto por el PSOE exigió como punto de partida potenciar el Ministerio de Defensa como órgano de la administración central. Desde el órgano central se iba planear, dirigir y gestionar todo el proceso de cambio. Quedó reforzada la línea administrativa y de gestión frente a la línea del mando militar. La desconfianza ante lo militar seguía presente. Se olvidó el principio básico de que toda acción lleva aparejada una reacción. Cada uno de los ejércitos trató de asegurar su influencia en las parcelas que pudo. La decisión política supuso absorber y concentrar en el mismo órgano central las competencias políticas, administrativas 
y militares. Los consejos superiores de los tres ejércitos quedaron relegados a desempeñar funciones de asesoramiento y de consulta. En no pocas ocasiones y ante la rapidez con la que se actuaba, los consejos asesores quedaron reducidos a meros receptores de las decisiones que se les hacía llegar sin que hubieran participado en su propuesta o estudio. Aparecieron tonos disonantes y de desconfianza entre colegas destinados en puestos de la administración y los que permanecían en las unidades, al tiempo aumentaron los recelos entre quienes tenían que gestionar y actuar de manera coordinada. En términos orgánicos, las fuerzas armadas, ejército de tierra, armada y ejército del aire se reformaron siguiendo la misma estructura para los tres: cuartel general, fuerza y apoyo a la fuerza. Desaparecieron las capitanías generales, cargadas de fuertes connotaciones históricas, simbólicas y políticas, siendo sustituidas por las funcionales y neutrales zonas militares, marítimas y aéreas. El objetivo final de la reforma socialista no era otro que conseguir unas fuerzas armadas reducidas y operativas. No era fácil conseguir estos dos objetivos al mismo tiempo. Fueron años donde se contó con menores recursos presupuestarios en razón del impacto de la crisis económica y por la potenciación de otros capítulos del presupuesto nacional. El número de unidades y mandos se redujo de manera importante, pero los ahorros no se invirtieron en maniobras y en la modernización del material. A partir de entonces la reducción de la instrucción se ha visto compensada con ejercicios en simuladores y con la participación creciente de grupos de militares en actividades desarrolladas en el marco de la OTAN y la UEO.

Las reformas se sucedieron sin dar tiempo para medir los resultados. Ante el nuevo papel de España en los escenarios internacionales se propuso un nuevo concepto de fuerzas armadas. Dejaba de ser una organización militar de carácter territorial para proyectar su acción en las nuevas misiones. El ejército de tierra se organizó alrededor de la fuerza permanente, formada por unidades que constituyen la fuerza de maniobra; las de defensa de área (islas, Ceuta y Melilla); fuerzas para la acción conjunta y una reserva movilizable. La armada se articuló en la flota, que incluyó las principales unidades de combate, y las fuerzas marítimas de zona encargadas de la vigilancia. El ejército del aire siguió los criterios de la Alianza Atlántica al organizar sus unidades alrededor del combate y su apoyo, junto con las fuerzas auxiliares. La reducción de las plantillas de las fuerzas armadas era otro de los objetivos de la reforma. La herencia histórica había llevado a que las fuerzas armadas contaran con un número de unidades siempre por encima de las necesidades reales de España, con unidades y cuadros de mando sin el adecuado número de soldados, y en no pocas ocasiones sin las dotaciones requeridas. Se exigía actuar sin dilación para adecuar las fuerzas armadas a la realidad política, económica y social de España como potencia media ${ }^{15}$. Nunca fue fácil ni cómodo resolver el problema de hipertrofia militar. Asumir los costes de la realidad siempre resulta incómodo, más todavía cuando se hace poco para cambiarla. 
El servicio militar se convirtió en el referente electoral y partidista en esta época de cambios profundos. La cuestión de la mili se convirtió en el punto sobre el que giraba de manera interesada y de forma torcida las cuestiones que tenían que ver con la seguridad y la defensa de España. Los acuerdos y compromisos internacionales que habían asumido los gobiernos de España, de indudable trascendencia política, apenas produjeron debate alguno ${ }^{16}$. Para conocer esta etapa crucial se hace imprescindible manejar los análisis de Félix Artega (Arteaga, 1999) y Bernard Labatut (Labatut, 1993) La reducción del tiempo de la prestación del servicio militar, nada más, se convirtió en el problema en el que todos opinaban de manera apasionada. De nuevo la parte sustituía al todo (Labatut y Paricio, 1996), (Sampedro, 1996) El tiempo de permanencia en filas se hizo igual para los soldados de los tres ejércitos, nueve meses. Durante un tiempo las fuerzas armadas contaron con soldados de reemplazo, voluntarios y voluntarios especiales que se comprometían a permanecer por un tiempo mayor en filas. La Constitución de 1978 reconoció a los españoles el derecho a la objeción de conciencia. En 1985 el Ministerio de Justicia redactó por fin leyes y normas correspondientes para regular esta situación y crear la Prestación Social Sustitutoria al servicio militar. A partir de ese momento aumentó todavía más el número de solicitantes. La objeción de conciencia terminó por convertirse en objeción de conveniencia. La ley era muy laxa a la hora de reconocer los motivos alegados por los solicitantes. Bastaba declarar razones de carácter ético, moral, filosófico o humanitario para que se reconociera el derecho sin que el demandante tuviera que aportar otras pruebas o documentos. La ley estableció el principio de que la solicitud tenía que ser resuelta en un plazo máximo de seis meses, trascurrido este tiempo sin ninguna respuesta se daba por supuesto que la petición había sido aceptada. Ante la avalancha de peticiones y la falta de recursos en el Ministerio de Justicia para analizarlas se produjo un sistemático fraude de ley que estimuló aún más el número de peticiones ${ }^{17}$. La tendencia se redujo de manera momentánea cuando se hizo un esfuerzo importante para gestionar las peticiones y para asignar destinos a los objetores. Duró poco el descenso. La reducción de objetores fue coyuntural y se recuperó la tendencia. Las peticiones siguieron creciendo con el paso del tiempo hasta que el gobierno del Partido Popular (PP) anunció el final del servicio militar obligatorio $^{18}$. Los plazos para su desaparición se fueron reduciendo de manera progresiva y acelerada. La sensación que se daba era la de que se carecía de un plan. La consecuencia lógica no podía ser otra que se redujera de manera importante el número de soldados de reemplazo que se mostraban dispuestos a cumplir con la obligación del servicio militar, al tiempo que aumentaba el número de jóvenes que se acogían a las prórrogas de incorporación, los que solicitaban la objeción de conciencia, o los que simplemente no acudían al llamamiento al comprobar que no les pasaba nada. El final del servicio militar obligatorio se fijó el 1 de enero de 2002. 
El PSOE propuso, desde los programas electorales que presentaba en la oposición, la organización militar en términos ocupacionales siguiendo los planteamientos teóricos de Charles C.Moskos. A partir de este principio quedó marcada toda la configuración jurídica de las fuerzas armadas y el planteamiento de la política legislativa de los distintos gobiernos socialistas. Los gobiernos del PP apenas lo han cambiado. La conclusión que cabe deducir de las reformas no resulta positiva (Escribano, 1998, pp. 49-90). Los argumentos críticos inciden, en primer lugar, en las normas sobre provisión de destinos. Los nombramientos para ocupar las vacantes más atractivas y con mayor proyección de la carrera militar se cubren mediante el procedimiento de libre designación, mientras que la antigüedad o el concurso de méritos se reservan para cubrir vacantes de importancia menor y de carácter burocrático. Apenas se ha hecho uso del concurso de méritos. Se redujeron las garantías de los procesos de evaluación y clasificación de los mandos. A los subordinados se les evalúa sin que lleguen a conocer el contenido de los informes de cuyo resultado depende su futuro en la profesión. El sistema de ascensos se rige en los primeros escalones del mando, al comienzo de la carrera militar, por el principio de la antigüedad; en los escalones intermedios por un mecanismo de cierta discrecionalidad que, en el caso de los mandos superiores llega a ser total. Se reconoce así la existencia de comportamientos típicamente clientelistas. El modelo ocupacional, planteado en términos de mercado laboral, no ha conseguido acercar los sueldos militares con igual exigencia de formación y dedicación al de los funcionarios de la administración del Estado. Se han creado agravios comparativos entre militares del mismo rango destinados en el órgano central de la administración militar y los destinados en las unidades operativas. Las leyes y reglamentos que trataban de reducir el número de las plantillas no previeron la posibilidad de trasvasar una parte de los militares a otros organismos de la administración civil, central, autonómica o municipal. A militares de determinados empleos y escalas se les ofreció la posibilidad de acogerse a la situación de reserva transitoria ${ }^{19}$. El acierto se produjo en la reforma de la justicia militar. El ejercicio de la jurisdicción militar quedó reducido al ámbito estrictamente militar, hasta ese momento se actuaba por razón de la persona o del lugar; se reforzó el principio de unidad jurisdiccional manteniendo un único e independiente poder judicial del Estado, y, en tercer lugar, se despojó al mando militar la potestad judicial que tenía asignada por la condición de mando, de esta manera quedó eliminada la autoridad judicial de los capitanes generales.

Superadas las excentricidades y la ambivalencias en la política de seguridad y defensa, España se integró de manera activa en todas las organizaciones de seguridad y defensa (Arteaga, 1999), (Buffotot, 1998), (Caracuel, 1997), (CuetoJordán, 2001). Jerôme Montes, del IEP de la Universidad Toulouse I acaba de presentar su tesis, dirigida por B. Labatut, sobre estas cuestiones. Las fuerzas armadas españolas comenzaron a participar en misiones fuera del territorio nacional. La valoración pública de las fuerzas armadas terminó por recuperarse de forma 
definitiva. Hay que matizar que la valoración es positiva siempre que se pregunta por las intervenciones de las fuerzas armadas en las nuevas misiones. La mejora reforzó todavía más el apoyo del nuevo modelo de organización militar profesional sin que haya tenido reflejo en un mayor interés por las cuestiones de la seguridad y la defensa. Buena parte de la opinión pública, los formadores de opinión, los intelectuales y el sistema de enseñanza siguen desentendiéndose de estos asuntos que se consideran ajenos y lejanos a los intereses y preocupaciones más inmediatas. Desaparecido el servicio militar, el único motivo de interés en estos asuntos, lo demás importa poco. La participación de tropas españolas en el extranjero ha reforzado la situación excéntrica que sigue produciéndose en este aspecto de la cultura política de los españoles. El argumento resulta contundente. Si los éxitos se han alcanzando con unos recursos escasos, reconocidos como tales por las mismas personas que se muestran satisfechas, no hay ninguna razón para prestar mayor atención a estas cuestiones y menos todavía para dedicarles recursos mayores para resolver los problemas reconocidos. Esta actitud de alejamiento de las cuestiones de la seguridad y la defensa contrasta con la plena integración de España en los organismos internacionales y su activa participación en misiones de paz. En ocasiones el entusiasmo político desborda las posibilidades reales. Queda como reto reducir estos desfases. Existe la declaración solemne del gobierno para hacerlo, Directiva de Defensa Nacional 1/2000, y el PSOE lo apoya, pero uno y otro no va más allá. La memoria histórica sigue teniendo su peso y sigue siendo selectiva en esta parcela. Los prejuicios siguen presentes. No es fácil la solución, aunque tampoco se hace mucho por ahora para encontrarla.

La realidad del presente y del futuro de las fuerzas armadas españolas se plantea en tres escenarios. Uno, cumplir el mandato constitucional; dos, participar junto con sus socios en los compromisos internacionales, tres, mantener el principio de solidaridad ante los problemas que requieran la ayuda humanitaria en sus distintas formas y lugares, actuando de manera individual o colectiva. La dimensión internacional de las fuerzas armadas españolas, así como la necesidad de actuar de manera coordinada e integrada dentro del marco de las Naciones Unidas, OTAN o UE está totalmente asumida (Ministerio de Defensa, 2000). Cuando se ha preguntado en este sentido a mandos, cadetes y soldados sus respuestas son contundentes, se acepta en todos los casos, las respuestas afirmativas están por encima del $75 \%$. Los estudios internos demuestran el proceso de convergencia de los militares españoles con sus colegas extranjeros en los aspectos que tienen que ver con actitudes, comportamientos profesionales, manejo de símbolos y lenguajes, participación en escenarios culturales diversos, procedimientos, etc. Los miembros de las fuerzas armadas han asumido sin mayores problemas y en poco tiempo la nueva realidad de la seguridad y defensa compartida. Los esfuerzos por mantener la autonomía nacional en cuestiones de defensa hace tiempo que fueron desechados por la mayoría de los militares españoles, incluso mucho antes de que España formara parte de las organizaciones internacionales. 
A partir del nuevo escenario internacional que se abrió con el final del mundo bipolar, las fuerzas armadas españolas, al igual que las fuerzas armadas de los países avanzados, se encuentran inmersas en un proceso de crisis cuyas causas son positivas (Paricio, 2001) Por un lado las fuerzas armadas tienen que definir la nueva doctrina con la que hacer frente a los nuevos riesgos y amenazas; deben encontrar el modelo de organización rígidamente flexible capaz de integrar las diferentes misiones que se les encomiendan, y el militar de carrera debe encontrar nuevo sentido a la profesión militar en el nuevo escenario. Esta crisis se tiene que gestionar en un espacio donde se asume que los recursos humanos, económicos y materiales van a ser cada vez más escasos; donde lo militar debe encontrar acomodo en el nuevo Estado que surge a partir del proceso de integración europea, al tiempo que se debe llenar de contenido la identidad europea de seguridad y defensa común. Como se comprueba a partir del análisis comparado, poner orden a tantos factores no está resultando fácil a ninguna organización militar. Si complejo resulta encontrar acomodo a los problemas materiales, económicos y de organización, no menos complejo resulta solucionar el control de la frustración, anunciada por Morris Janowitz en 1960 (Janowitz, 1967), resultado del nuevo modelo de organización militar que anticipó y que es el de ahora mismo. A partir del análisis de las tendencias que muestran los datos de las encuestas de calidad de vida en el trabajo levantadas por el Ministerio de Trabajo (Ministerio de Trabajo, 2000) se deduce que también la anticipación también se ha cumplido en las fuerzas armadas españolas. Una vez asumido que el futuro de la profesión militar no es responsabilidad exclusiva del militar, descansa en la vitalidad del liderazgo político, va de suyo que la frustración debe ser necesariamente eliminada. Si no se hace, no debe extrañar la incertidumbre y el desánimo que muestran los militares de carrera en el presente y ante su futuro. La tendencia de los datos de las encuestas citadas es contundente en la denuncia. Hay que decir, sin que sirva de remedio que también en esto coinciden con los militares de las fuerzas armadas de sociedades avanzadas. Para terminar conviene citar el remedio propuesto por Janowitz. "Primero, limitar los objetivos militares a aquellas metas consideradas posibles y realizables; segundo, ayudar a la formulación de la doctrina militar, en la medida en que esta se convierta en la expresión unificada de los objetivos políticos nacionales; tercero, mantener un sentido de autoestima profesional en los hombres de las armas; y cuarto, crear nuevos recursos para el ejercicio del control político democrático" (Janowitz, 1967; p. 420). No se discute que es el reto más importante al que hay que hacer frente en el arranque del nuevo ciclo de las fuerzas armadas. Un reto para los militares y también para los civiles, sean políticos, intelectuales, formadores de opinión o universitarios. Cada cual, con críticas bien intencionadas o mostrando afecto, y en cualquier caso sin renunciar a sus convicciones, no puede dejar de echar su cuarto a espadas en este asunto si no quiere abandonar el papel que le corresponde en la sociedad moderna. 


\section{NOTAS}

(*) Este artículo se redactó inicialmente para la revista Pole Sud. Revue de Science Politique de l'Europe Méridionale. Es una publicación del "Observatorio de Políticas Públicas en la Europa del Sur" (OPPES) localizado en la Universidad de Montpellier. El artículo inicial es un producto más de la colaboración que mantiene el grupo de sociología militar de la Asociación Castellano Manchega de Sociología con los colegas de la Universidad de Montpellier.

${ }^{1}$ En la tarde del 23 de Febrero de 1981, cuando se estaba votando la candidatura de Leopoldo Calvo Sotelo para presidente del Gobierno, el Congreso de los Diputados fue asaltado por el Teniente Coronel de la Guardia Civil Antonio Tejero Molina. Lo hizo al mando de unos oficiales, suboficiales y guardias civiles. En aquel momento el Tte. Cnl. Tejero no era el mando orgánico, natural, de los guardias civiles que invadieron el Congreso. Una razón más que se añade al esperpento.

${ }^{2}$ Leopoldo Calvo Sotelo se propuso acelerar el proceso de integración de España en las organizaciones europeas y solicitar el ingreso de España en la OTAN. Se comprometió a celebrar el juicio militar y dejó claro que la sentencia sería recurrida ante la máxima instancia de los tribunales civiles (Calvo Sotelo, 1990).

${ }^{3}$ El coraje político se explica por el convencimiento de sus decisiones y el cumplimiento de las promesas de gobierno en una situación de manifiesta debilidad política. Tomó posesión tras un golpe de Estado del que se desconocía casi todo. La situación económica había entrado en una fase de recesión. La acción terrorista de ETA comenzó una nueva escalada. Su partido estaba dividido y algunos de sus miembros más significativos se habían pasado al PSOE. En el Parlamento se iba a enfrentar a una dura y bien preparada oposición. Sabía que la opinión pública que nutría a su partido desconfiaba cada vez más de su capacidad para gobernar. Medios de comunicación y formadores de opinión le daban la espalda. Las encuestas demostraban con rotundidad que se consolidaba la tendencia ascendente del voto socialista. La mayoría del electorado, incluso el conservador, aceptaba la idea de que el próximo gobierno sería socialista. El análisis de encuestas electorales de la época señalan que no pocos militares también apostaban por el cambio. Calvo Sotelo aceptó desde el primer momento que su tiempo al frente del gobierno iba a ser breve. Frente a realidad tan negativa para él y para su equipo podía haber dejado pasar los días trasladando a sus sucesores la resolución del nuevo problema militar. No lo hizo. Asumió el reto y cumplió todos y cada uno de los objetivos que se había fijado. Una vez alcanzados, disolvió el Parlamento. Convocó elecciones en el otoño de 1982 y las perdió, como estaba previsto. El PSOE alcanzó la mayoría absoluta. La transición política daba un paso más hacia la normalidad.

${ }^{4}$ Jaime Balmes, sacerdote y filósofo, vivió entre 1810 y 1848 . Fue también un sutil y crítico ensayista de la vida política española que le llevó al destierro en Francia.

${ }^{5}$ Este punto es uno de los temas recurrentes que cada cierto tiempo plantea la controversia con los partidos nacionalistas, de manera especial los nacionalistas vascos. Sus argumentos victimistas se justifican en términos de la amenaza latente que, según ellos, ejercen las fuerzas armadas sobre los distintos gobiernos. Según los nacionalistas la presión tiene como fin controlar y recortar la autodeterminación del país vasco. No han faltado las 
declaraciones de altos mandos militares que insisten que las fuerzas armadas son una organización del Estado, dependen del gobierno, y actúan de acuerdo con lo que dispone el Parlamento. Hay que destacar la habilidad y serenidad de las fuerzas armadas para no caer en la provocación de los terroristas de ETA al atentar de manera sistemática contra militares. El problema del terrorismo no se ha militarizado. El terrorismo queda reducido a una cuestión política y policial. No se quería volver al pasado, a la utilización política de las fuerzas armadas por medio de la justicia militar. Fueron tiempos donde el orden público se militarizó. Así lo señalaba el artículo 37 de la Ley Orgánica. Pocos militares se encontraban cómodos teniendo que aplicar justicia, no estaban preparados y no era su función. Algunos altos mandos, próximos a Franco y a lo que representaba, se quejaron con insistencia del uso interesado que se hacía del código de justicia militar. La experiencia negativa del juicio y ejecución de Grimau en 1963, dirigente comunista juzgado por delitos cometidos en la Guerra Civil, y el Juicio de Burgos, 1970, donde se juzgo y condenó a muerte a los primeros etarras, conmutadas después las condenas, repercutieron de manera negativa sobre las fuerzas armadas que aparecían como clase de apoyo del régimen autoritario, muy a su pesar. En los últimos años del régimen se creó el Tribunal de Orden Público (TOP), tribunal excepcional y civil (Águila, 2001). La justicia militar quedó reducida al ámbito de las fuerzas armadas.

6 En 2001 se cumplieron veinte años de estos sucesos. Ha pasado el tiempo necesario para que dejen de ser considerados como delito y que puedan ser perseguidos por la justicia. Se publicó un número importante de libros que volvieron a narrar con algún detalle nuevo lo que había ocurrido y poco más (Fernández, 2000). A partir de los nombres que aparecen en los libros se puede hacer el listado de actores y simpatizantes con los militares golpistas. Con la excepción de un general del que se sabía poco sobre su implicación en la conjura y que reconoció en ese momento su participación activa en el golpe, la lista de militares comprometidos no se ha ampliado. Sabino Fernández Campo declaró al Faro de Vigo: "Viví el 23-F, pero aún tengo muchas dudas y pocas ganas de despejarlas". El juez instructor, militar, encargado de la investigación no entró en mayores investigaciones (García Escudero, 1995). Se aceptó el riesgo que suponía esta decisión. Ante la inconsistencia que presentaron los golpistas se decidió no ir más allá en la investigación. Se acusó y juzgó nada más que a los protagonistas visibles. No se olvide que el intento de golpe de Estado fue televisado y radiado en directo. Poco tiempo después publiqué un artículo donde demostraba que el golpe se venía preparando con bastante antelación, y que fue el resultado de la crónica de un golpe anunciado (Paricio, 1990). Poco o nada se hizo a los militares que simpatizaban con el golpe, como tampoco se molestó a los que participaron en segunda o tercera fila. La mayoría han desarrollado su carrera militar con normalidad, han ascendido y algunos han alcanzando destinos de cierta importancia, incluso en mejores condiciones que los militares que hicieron manifestación de su compromiso democrático. Baste citar como anécdota que uno de los oficiales de la Guardia Civil, encargado de la información y seguridad en aquellos sucesos, explica temas de contrainsurgencia en la universidad en su condición de oficial en activo y con rango superior al de entonces.

${ }^{7}$ Lo que sí se produjeron fueron situaciones de sonoros silencios. Algunas instituciones, la iglesia española por ejemplo, grupos sociales o personalidades significativas no encontraron la oportunidad para condenar el golpe de Estado en los primeros momentos. 
${ }^{8}$ Investigación financiada por el Centro de Investigaciones Sociológicas (CIS) que no se publicó. Jesús Ignacio Martínez Paricio: "Encuesta a los militares de la transición: Las mentalidades militares".

${ }^{9}$ Se puede ver en el silencio de las declaraciones de los principales líderes del PSOE (Burns, 1996). Se reconoce en este texto que tuvieron que organizar de manera apresurada algunas reuniones para ponerse al corriente de lo militar. Hay un caso llamativo. Se trata de Julio Busquets, militar cofundador de la Unión Militar Democrática, organización militar clandestina surgida en 1974 bajo el influjo de la Revolución de los Claveles de Portugal que se disolvió tras las primeras elecciones democráticas, verano de 1977. Fue catedrático de sociología, una vez retirado del ejército, diputado por el PSOE y Vicepresidente de la Comisión de Defensa en el Congreso de los Diputados. Declaró a al prensa que "con los datos que teníamos no nos podíamos enterar de nada". El capítulo de sus memorias donde describe el golpe de estado no aporta nada nuevo (Busquets, 1999). ${ }^{10}$ El CIS aplicó una el día 27 de febrero de 1981. Los resultados indicaban el comienzo de una opinión más positiva ante lo militar. A partir de entonces la tendencia se ha ido consolidando.

${ }^{11}$ El CIS dejó de preguntar en sus barómetros de opinión sobre la posibilidad de un nuevo golpe militar, la aceptación de la democracia por parte de los militares, o si las fuerzas armadas seguían siendo un grupo político. Las respuestas que se obtenían eran unánimes al señalar que habían desparecido las amenazas y que los militares habían asumido la democracia. Por parte de formadores de opinión, incluso políticos relevantes, la desconfianza y los recelos se mantuvieron durante más tiempo y algunos todavía los mantienen. Otros datos de opinión y su interpretación se pueden ver en Díez Nicolás (1999). Los datos del CIS se pueden consultar en: www.cis.es

12 Comunicación de Julio Busquets en el Congreso Nacional de Sociología. Destacó como modelo de referencia el de las fuerzas armadas alemanas. Se pretendía alcanzar para España el modelo de ciudadano soldado de la Bundeswehr. Reconoció que se cometieron errores importantes que terminaron por alejar a no pocos militares que vieron frustradas las expectativas que había levantado la llegada del PSOE al gobierno. No fueron los únicos frustrados. A partir de entonces el apoyo electoral al PSOE cambió al PP.

${ }^{13}$ Felipe González sigue reconociendo como una de las etapas más difíciles de sus años de gobierno la preparación del referéndum (González, 2001). Hipotecó buena parte de su prestigio y del PSOE para conseguir dar la vuelta a su mensaje inicial: "OTAN, de entrada no". Hizo todo lo posible para que un número importante de indecisos apoyara el sí a la permanencia de España en la OTAN. Todas las encuestas indicaban el triunfo del no. Partidos conservadores pedían a sus electores la abstención, y los partidos de izquierda reclamaban el rechazo a la OTAN. El referéndum de la OTAN es un ejemplo de ingeniería electoral. El gobierno realizó todo tipo de esfuerzos para movilizar a las más diversas personalidades, intelectuales y formadores de opinión para que dejaran a un lado sus ideas personales y apoyaran la propuesta. Los costes económicos que supuso este esfuerzo terminó afectando a las finanzas del partido. El PSOE quedó dividido y se radicalizaron las posturas tanto de sus miembros de base, como de la dirección. La más izquierdista, populista, planteaba el voto negativo como forma de mantener a España en la corriente de no-alineación, frente a los que defendían la necesidad de modernizar y europeizar, 
cuando no de americanizar, el partido y España. El presidente tuvo que comprometer su prestigio personal para obtener el voto favorable. Los españoles que se encontraban en destinos OTAN describen la inquietud y el desánimo con el que tuvieron que trabajar el día del referéndum haciendo las maletas y devolviendo documentación pues se daba por supuesto que tendrían que abandonar Bruselas. El resultado fue favorable por un margen estrecho. El análisis de este proceso electoral se puede ver en Val Cid (1996).

${ }^{14}$ En tiempos de la oposición, en el PSOE dominaba la postura contraria a la política de bloques. En la crítica a la UCD aprovechó el debate de política exterior para utilizarlo en una maniobra de política interior para desgastar al partido en el gobierno dada la impopularidad del tema de la OTAN, los bloques militares y las bases norteamericanas.

${ }^{15}$ La hipertrofia de mandos ha sido una constante a lo largo del siglo pasado. Se remonta a finales del siglo XIX. Pocas veces el final de una guerra llevó aparejada la desmovilización de las unidades que habían combatido. Los regimientos seguían existiendo aunque contaran con un número reducido de efectivos. El final de la Guerra Civil coincidió con el estallido de la Segunda Guerra Mundial, lo que impidió de nuevo la reducción de cuadros y unidades. $\mathrm{Al}$ acabar el conflicto mundial exigía reducir el tamaño de las fuerzas armadas españolas. Las leyes que lo intentaron no tuvieron el efecto esperado. No era fácil encontrar acomodo al número importante de mandos que ya no se necesitaban, más todavía cuando eran militares con una edad mediana y con una formación estrictamente militar. Los militares que tenían alguna especialidad no tuvieron tantos problemas para reintegrarse en la vida civil. Algunos pasaron a puestos en la administración central del Estado. Se puede consultar Arteaga (1999), Busquets (1989), Comas (1986), Fernández (1998), Marquina (1986), Olmeda (1988), Paricio (1999), Platón (2001).

${ }^{16}$ En las primeras etapas de la transición política los partidos habían llegado al acuerdo de no llevar al debate parlamentario las cuestiones que tenían que ver con las fuerzas armadas. Se quería evitar que la confrontación política pudiera terminar "provocando recelos entre los militares, implicándoles en las discusiones de partido", según comentó Javier Rupérez, actual embajador de España en Estados Unidos. Por esta razón se hizo un uso abusivo del decreto ley que evitaba el debate previo de las disposiciones que tenían que ver con la cuestión militar.

${ }^{17}$ Desde enero de 1985 hasta septiembre de 2000, últimos datos disponibles, se presentaron 988.203 solicitudes de objeción, y se reconocieron 945.195. La situación se complicó cuando algunos objetores se negaron a cumplir la Prestación. Apareció la figura del insumiso. Seguían abiertos 4.771 expedientes a insumisos. La opinión pública terminó reconociendo que la objeción de conciencia respondía a intereses particulares que nada tenían que ver con los nobles principios que amparaba la Constitución. A pesar de todo, esta

conducta se valoraba de forma positiva (77\%), incluso la insumisión (53\%), y la mayoría (79\%) consideraba que no tenía que ser un delito. El descrédito del servicio militar llegó a tal extremo que una parte significativa de los entrevistados consideraban que tampoco debía ser delito la deserción militar (69\%). Cabe señalar como algo más que anécdota la declaración de un ex portavoz del Ministerio de Defensa que en una intervención en la radio donde presentaba el nuevo modelo de servicio militar profesional, reconoció que él también falsificó un certificado médico para librarse del servicio militar. www.mju.es/ objecion/. Una vez más la imprevisión cogió desprevenido a quien no tenía que estarlo. 
El legislador no había previsto que al desparecer el servicio militar habría que adaptar los reglamentos que regulaban el principio de igualdad constitucional entre el servicio militar y la prestación social sustitutoria. Al final, la insumisión y la deserción han desparecido del Código Penal

${ }^{18} \mathrm{La}$ aceleración del proceso que puso fin al servicio militar obligatorio fue consecuencia del resultado electoral de 1996 que llevo al PP a gobernar en una situación de minoría mayoritaria en el Parlamento. En el programa electoral había propuesto reducir de forma progresiva el servicio militar obligatorio al tiempo que iría aumentando, se pensaba, el número de soldados voluntarios. Su debilidad parlamentaria le obligó a negociar con Convergencia y Unión (CiU) el apoyo para alcanzar la presidencia. El acuerdo exigió que se pondría fin al servicio militar en una fecha concreta. Sin contar con los estudios necesarios y menos todavía sin tomar las decisiones oportunas, se anunció la decisión en el proceso de investidura en el Parlamento. Ante la propuesta el número de objetores aumentó todavía más. Desde hacía años los datos de las encuestas venían reclamando la necesidad de contar con un modelo de fuerzas armadas donde los soldados fueran voluntarios. A esos soldados se les ha denominado de manera equivocada como soldados profesionales. Encuestas realizadas a distintos grupos de militares también deseaban este tipo de soldados. En la armada y en el ejército del aire la opinión era mayoritaria, en el caso del ejército de tierra la opinión estaba dividida. Se valoraba al nuevo soldado pero se avisaba de la perdida de operatividad de algunas unidades y dependencias militares si el tránsito hacia el nuevo modelo no se hacía con cuidado. En la VI Legislatura, 19962000, se fijó entre 150.000 y 170.000 el total de efectivos de las fuerzas armadas, incluyendo los cuadros de mando. De acuerdo con las declaraciones de los responsables del reclutamiento militar, las cifras son un $25 \%$ menos de lo previsto. Al problema del reclutamiento voluntario, poco más de un aspirante por plaza convocada y la tendencia sigue bajando la proporción, existiendo diferencias para cada ejército y determinados puestos, se añade el de retener y renovar los contratos de los soldados al final de su compromiso. En este caso el problema es todavía mayor.

${ }^{19}$ El militar que se acogía a esta situación dejaba el servicio activo. Percibía las retribuciones íntegras netas de acuerdo con el empleo militar; se les aseguraba un ascenso, y podía ejercer actividades laborales de carácter privado. Las condiciones resultaban muy favorables en unos momentos económicos y laborales críticos para el resto de la población laboral. Debe destacarse que esta opción no provocó un movimiento de protesta, ni tampoco de crítica por parte de los sindicatos, o en la opinión pública. Un indicador más que demuestra que las cuestiones militares apenas interesaban a unos pocos. Militares que no se acogieron a esta situación esperaban que su carrera militar terminaría siendo gratificante. Se vieron doblemente frustrados. Para la mayoría no mejoró su situación profesional, y comprobaron que los compañeros que habían abandonado las fuerzas armadas se encontraban en una situación mucho más acomodada. 


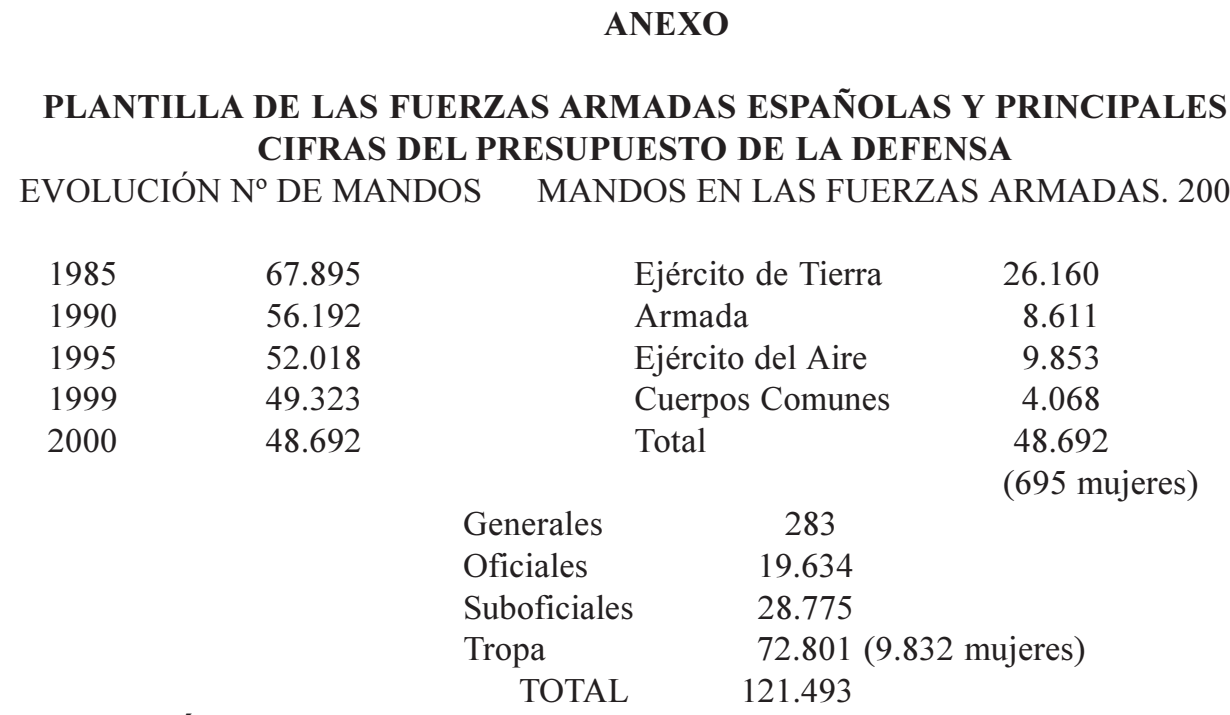

EVOLUCIÓN DE LAS MACRO-MAGNITUDES DEL PRESUPUESTO DE DEFENSA

Millones euros

$\%$ del Presupuesto

$\%$ del PIB

General del Estado

$\begin{array}{llll}1997 & 5.226,44 & 4,8 & 1,06 \\ 1998 & 5.391,22 & 4,95 & 1,02 \\ 1999 & 5.575,99 & 4,92 & 0,99 \\ 2000 & 5.799,77 & 4,88 & 0,96 \\ 2001 & 6.060,77 & 4,87 & 0,94 \\ 2002 & 6.320,21 & 5,61 & 0,92\end{array}$

\section{DISTRIBUCIÓN DEL PRESUPUESTO 2000}

Órgano Central

26,6

Estado Mayor de la Defensa $\quad 1,4$

Ejército de Tierra 38,1

Armada

16,9

Ejército del Aire

17

Total

$100 \%(5.799,77$ euros $)$

Fuente: Ministerio de Defensa. Dirección electrónica indicada.

DISTRIBUCIÓN DEL GASTO EN DEFENSA POR APARTADOS

1990-94

1995

1997

1999

Personal

64,9

65,7

66,1

66,6

Material

12,4

13,6

13,6

12

Infraestructura

1,2

0,7

0,7

1,8

Otros gastos

21,2

20

19,6

19,6

TOTAL

$100 \%$

Fuente: OTAN. www.nato.int 


\section{BIBLIOGRAFÍA}

ÁGUILA, JJ., (2001): El TOP. La represión de la libertad (1963-1977), Planeta, Barcelona. ARTEAGA, F., (1999): La identidad de Defensa y Seguridad en Europa. El pilar estratégico de la Unión, Política Exterior, Madrid.

BALMES, J.,(1950): "La preponderancia militar". Obras completas. Escritos políticos, Biblioteca de Autores Cristianos, Madrid.

BUFFOTOT, P., (ed.) (1998):La défense en Europe. Les adadptations de l'après-guerre froide, La documentation Française, Paris.

BURNS MARAÑÓN, T., (1996): Conversaciones sobre el Socialismo, Plaza \& Janés, Barcelona.

BUSQUETS, J., (1989): El militar de carrera en España, Ariel, Barcelona.

BUSQUETS, J., (1999): Militares y demócratas. Memorias de un fundador de la UMD y diputado socialista, Plaza \& Janés, Barcelona.

CALVO SOTELO, L., (1990): Memoria viva de la transición, Plaza \& Janés, Barcelona. CARACUEL RAYA, MA., (1997): Los cambios de la OTAN tras la guerra fría, Tecnos, Madrid.

CASTILlEJO, J., (1976): Guerra de ideas en España, Revista de Occidente, Madrid.

COMAS, JM. Y MANDEVILLE, L., (1986): Les militaires et le pouvoir dans l'Espagne contemporaine de Franco à Felipe Gonzalez, Presses de l'Institut d'Études Politiques de Toulouse.

CUETO, C. Y JORDÁN, J., (2001): Introducción a los estudios de seguridad y defensa, Comares, Granada.

DÍEZ NICOLÁS, J., (1999): Identidad Nacional y Cultura de Defensa, Síntesis, Madrid. ESCRIBANO TESTAUT, P., (1998): “La carrera militar tras la Ley 17/1989”,Revista Española de Derecho Militar, núm. 71. Enero-junio 1998.

FERNÁNDEZ LÓPEZ, J., (1998): El Rey y otros militares. Los militares en el cambio de régimen político en España (1969-1982), Trotta, Madrid.

FERNÁNDEZ LÓPEZ, J., (2000): Diecisiete horas y media. El enigma del 23-F, Taurus, Madrid.

GARCÍA ESCUDERO, JM., (1987): Los españoles de la conciliación,Espasa Calpe, Madrid.

GARCÍA ESCUDERO, JM., (1995): Mis siete vidas. De las brigadas anarquistas a juez del 23-F, Planeta, Barcelona.

GONZÁLEZ, F. Y CEBRIÁN, JL.,(2001): El futuro ya no es lo que era. Una conversación, Aguilar, Madrid.

JANOWITZ, M., (1967): El soldado profesional. Retrato político y social, Omeba, Buenos Aires. Hay una edición reciente del Ministerio de Defensa.

LABATUT, B., (1993): Renaissance d'une Pusissance? Politique de défense et reforme militaire dans l'Espagne démocratique,Economica, Paris.

LABATUT, B., Y PARICIO, JIM., (1996): “Espagne: vers l'armée de métier”,Défense Nationale, Novembre, 1996.

MARQUINA, A., (1986): España en la política de seguridad occidental. 1939-1986, Ediciones Ejército, Madrid. 
MINISTERIO DE DEFENSA (2000): Libro Blanco de la Defensa,www.mde.es MINISTERIO DE TRABAJO Y ASUNTOS SOCIALES (2000): Encuesta de calidad de vida en el trabajo, eclsint@mtas.es

OLMEDA, JA., (1988): Las Fuerzas Armadas en el estado franquista, El Arquero, Madrid. PARICIO, JIM.,(1990): "Militares y ejército en España: 1898-1998", Salvador Giner: España, Sociedad y política,Espasa Calpe, Madrid.

PARICIO, JIM., (1991): "Defensa nacional y militares en el umbral del nuevo siglo". José Vidal-Beneyto (Ed.), España a debate. La política, Tecnos, Madrid.

PARICIO, JIM., (1999): Le monde méconnu de nos militaires, Centre d'Études en Sciences Sociales de la Défense, París.

PARICIO, JIM.,(cord),(2001): La ética en las nuevas misiones de las fuerzas armadas, Ministerio de Defensa, Madrid.

PLATÓN, M., (2001): Hablan los militares. Testimonios para la historia (1939-1996), Planeta, Barcelona.

RIDRUEJO, D., (1964): Escrito en España, Losada, Buenos Aires.

SAMPEDRO BLANCO, P., (1996): Nuevos movimientos sociales. Agendas políticas e informativas: el caso de la objeción de conciencia, Instituto Juan March de Estudios e Investigaciones, Madrid.

VAL CID, C., (1996): Opinión pública y opinión publicada. Los españoles y el referéndum de la OTAN, CIS, Madrid. 